\section{References}

1. Tiwari RR, Saha A, Parikh JR. Respiratory morbidities among working children of gem polishing industries, India. Toxicology and Industrial Health 2009; 25: 81-4.

2. White NW, Chetty R, Eric D. Bateman. Silicosis among gemstone workers in South Africa: Tiger's-eye pneumoconiosis. American Journal of Industrial Medicine 2007; 19: 205-13.

3. Huang Li-rong, Chen Su-sheng, LI Jun-hui, et al. Study on pulmonary functions in 53 patients with gem's silicosis. Chinese Occupational Medicine 2004; 3: 9.

4. Kern DG, Hanley KT, Roggli VL. Malignant mesothelioma in the jewelry industry. American Journal of Industrial Medicine 1993; 21: 409-16.

5. Dossing M, Langer SM. Asbestos-induced lung injury among Danish jewelry workers. American Journal of Industrial Medicine 1994; 26: 755-8.
6. Wegner R, Heinrich-Ramm R, Nowak D, Olma K, Poschadel $\mathrm{B}$, Szadkowski D. Lung function, biological monitoring, and biological effect monitoring of gemstone cutters exposed to beryls. Occupational and Environmental Medicine 2000; 57: 133-9.

7. Sparks PJ, Wegman D. Cause of death among jewelry workers. Journal of Occupational Medicine 1980; 22: 733- 6.

8. Hayes RB, Dosemeci M, Riscigno M, et al. Cancer mortality among jewelry workers. American Journal of Industrial Medicine 1993; 24: 743-51.

9. Ng TP, Tsin TW, O'Kelly FJ, Chan SL. A survey of the respiratory health of silica-exposed gemstone workers in Hong Kong. The American Review of Respiratory Disease 1987; 135: 1249-54.

10. Ghotkar VB, Maldhure BR, Zodpey SP. Involvement of Lung and Lung Function Tests in Stone Quarry Workers. The Indian Journal of Tuberculosis 1995; 42: 155-60.

\title{
Kikuchi-Fujimoto's disease: a case series from Sri Lanka
}

\author{
R A Abeysekera ${ }^{1}$, S A M Kularatne ${ }^{2}$, R Waduge $^{3}$, A G W Sandeepana ${ }^{1}$, J M R P Bandara ${ }^{1}$, \\ I V B Imbulpitiya ${ }^{1}$
}

(Index words: Kikuchi-Fujimoto's disease, necrotising lymphadenitis)

\begin{abstract}
Introduction Kikuchi's disease is a rare, benign, selflimiting disease, mainly involving the lymph nodes of young people. The etiology is unknown. Clinical symptoms and basic investigations may mimic lymphomas and chronic granulomatous conditions like tuberculosis. Lymph node biopsy shows characteristic diagnostic features. Even though described internationally, the local disease pattern or incidence has not been well studied. Methods We studied all patients who were diagnosed with Kikuchi's disease at Teaching Hospital, Peradeniya from January 2011 to April 2012.

Results A total of 9 cases showed histopathological features of Kikuchi's disease. All patients were females, in the age group of 12-30 years having fever and lymphadenopathy. They carried a provisional diagnosis of lymphoma, tuberculosis or reactive lymphadenitis.
\end{abstract}

Conclusions Necrotising lymphadenitis has a predilection for cervical lymph nodes of females and is usually accompanied by fever. Clinical features can resemble tuberculous lymphadenitis or malignant lymphoma. Excision biopsy of the involved node is mandatory for the diagnosis.

Ceylon Medical Journal 2013; 58: 31-33

\section{Introduction}

Histiocytic necrotising lymphadenitis was first described independently in 1972 by Kikuchi and Fujimoto from Japan [1,2]. Hence, the entity is also known as KikuchiFujimoto's disease or simply Kikuchi's disease (KD). It classically presents as a painful cervical lymphadenopathy in young adults, usually females. Unilateral involvement of the posterior cervical group is the commonest picture.

${ }^{1}$ Medical Unit, Teaching Hospital Peradeniya, Departments of ${ }^{2}$ Medicine and ${ }^{3}$ Pathology, Faculty of Medicine, University of Peradeniya, Sri Lanka.

Correspondence: RAA, email: <rajithaasa5@hotmail.com>. Received 10 July and revised version accepted 11 October 2012. Competing interests: none declared. 
Although most cases have been reported in the Oriental races, the entity has also been described in the Caucasian, Hispanic, Middle Eastern and Indian populations. Less common manifestations include fever, axillary and mesenteric lymphadenopathy, splenomegaly, parotid gland enlargement, cutaneous rash, arthralgia, myalgia, aseptic meningiti, bone marrow haemophagocytosis and interstitial lung disease [4-6]. The cutaneous lesions include erythematous macules, papules, plaques and nodules [7].

The aetiology is unknown, although a viral or autoimmune pathogenesis has been suggested. Several articles have described an association of KD with autoimmune disorders, notably systemic lupus erythematosus (SLE), mixed connective tissue disease and Still's disease. The strongest link is with SLE, although the exact nature of this association has yet not been established [8]. The most important differential diagnoses to consider in patients presenting with typical features of KD are tuberculous lymphadenitis and malignant lymphoma. Two cases of KD occurring in the course of remission of diffuse large B-cell lymphoma have been reported [9]. Immunohistochemistry can be used to differentiate KD from malignant lymphoma. The disease is usually selflimiting with symptoms resolving within a period of 6 months. However, two fatalities have been reported in the literature $[10,11]$. One was a 38 year-old patient who died of abrupt heart failure and the second was a case of fatal pulmonary haemorrhage. The risk of recurrence is low, with two large studies reporting a range of $3.3 \%$ to $4 \%$ $[1,12]$. Blood investigations are non-specific, but may reveal a leucopenia, atypical lymphocytosis or elevated erythrocyte sedimentation rate (ESR). The diagnostic test of choice is an excision biopsy of the involved lymph node which shows patchy areas of necrosis with karyorrhexis, especially in the cortical and para-cortical areas. As previously mentioned, KD is a self-limited disease with spontaneous resolution of symptoms in almost all cases within a six-month period. Systemic steroids have been found to be of symptomatic benefit in a few cases [13].

Though the disease pattern in other countries have been described, no local data is available regarding the disease pattern or incidence in Sri Lanka. Therefore this study was carried out to evaluate the disease pattern of $\mathrm{KD}$ in Sri Lanka.

\section{Methods}

Study was conducted as a case series study where all patients who were diagnosed with KD at the Medical Unit, Teaching Hospital Peradeniya from January 2011 to April 2012 were included and followed up. Informed consent was taken from all patients prior to obtaining information. The pathologist reviewed all the slides to reconfirm the diagnose. We reviewed the case notes and collected the relevant data from patients and they were followed up for 6 months after initial diagnosis.

\section{Results}

During the study period, lymph node biopsies were done in 47 patients in the diagnostic workup of lymphadenopathy. Out of those, nine patients (19\%) were diagnosed with Kikuchi's disease during the study period. Other commonly diagnosed conditions with the help of the lymph node biopsy were tuberculosis $(n=10)$ and lymphoma $(n=16)$. Patients were mostly diagnosed towards the extremes of the year where 6 patients were diagnosed from January to March and 2 patients from October to December. One patient was seen in May 2011. In our series all were females. Seven were Sinhalese and two were Tamil in ethnic origin. The mean age was 21 (range 12-30) years. Eight of them had a presenting complaint of tender cervical lymphadeopathy with fever. One presented with fever and abdominal pain who later was found to have significant isolated inguinal lymphadenopathy. Lymph node involvement varied between patients but the commonest group involved was the cervical group. Two patients had hepatosplenomegaly. None of the patients had a rash. The average duration of fever was 18 days (range 2 - 40 days) though the lymph node enlargement persisted for an average of 2 months.

Table 1. Summary of the investigations

\begin{tabular}{lcccccc}
\hline & WBC & ESR & LDH & Mantoux & ANA & $\begin{array}{c}\text { BM } \\
\text { biopsy }\end{array}$ \\
\hline $\begin{array}{l}\text { No. of } \\
\text { patients }\end{array}$ & $(9 / 9)$ & $(9 / 9)$ & $(2 / 9)$ & $(3 / 9)$ & $(2 / 9)$ & $(1 / 9)$ \\
Mean & $5.3 \pm 2.8$ & $46 \pm 26$ & $1166 \mu / \mathrm{L}$ & 1 positive & negative & normal \\
Range & $2.4-9.9$ & $20-94$ & & & & \\
\hline
\end{tabular}

FNAC of the affected lymph node was performed in one patient and was inconclusive and suggested to exclude a lymphoproliferative disease.

There was no characteristic picture in the blood investigations, although there was a trend towards low white blood cell counts with almost equal percentage of lymphocytes and neutrophils. Except one patient who had a low platelet count of $136 \times 10^{3} / \mu \mathrm{L}$ all others had normal platelets. Three patients had low haemoglobin (10-11 g/dL). Blood pictures were inconclusive with six of them showing features of viral infection. Renal functions and liver enzymes were normal. It was interesting to note the very high LDH levels in the two patients whose $\mathrm{LDH}$ level was tested.

The Mantoux test became positive in one patient. Two patients were tested for ANA which turned out to be negative. Bone marrow was performed in one patient which was normal.

The initial working diagnosis had been lymphoma (3 out of 9), tuberculosis (3/9), infectious mononucleosis $(1 / 9)$, reactive lymphadenitis (1/9) and suppurative 
lymphadenitis (1/9). The diagnosis was established by excision biopsy in all 9 cases which showed histiocytic necrotizing lymphadenitis (Figure 1).

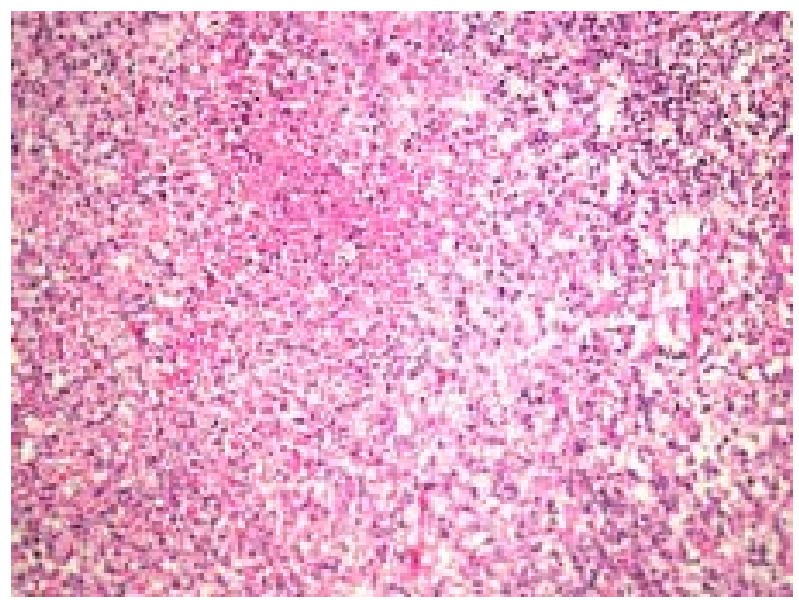

Figure 1. Lymphnode biopsy showing necrotizing areas with karyorrhectic debris. No neutrophil infiltration or granulomata around. (Haematoxylin and eosin stain x 400)

One patient was already diagnosed with a mixed connective tissue disorder whereas the other 8 patients were previously healthy. In the six months follow up of these patients no one had recurrences or had developed any other diseases such as connective tissue disorders, malignancy or tuberculosis. All patients were treated with oral coamoxyclav. Prednisolone was given to two patients as their fever was not responding and had severe pain due to lymphadenopathy. Both these patients responded to prednisolone.

\section{Discussion}

Our patient characteristics were similar to what has previously been described in the literature. One patient surprisingly had a positive mantoux test which has not been described before in the literature. Bone marrow biopsy and blood picture assessment as expected was inconclusive. FNAC of the lymph nodes was nonrevealing. Excision biopsy was the diagnostic test of choice. While FNAC is highly reliable in the identification of metastatic carcinoma and melanoma in lymph nodes obviating the need for excision biopsy, the case is not the same with malignant lymphomas [15]. High rates of falsenegatives and the prognostic importance of architectural assessment in some lymphoid tumours limit the role of FNAC. Seven out of the nine patients became asymptomatic with non-steroidal anti-inflammatory drugs where as 2 patients required oral prednisolone for symptom control. One patient with mixed connective tissue disorder developing KD in this study group may further strengthen the association between these diseases. Fever with generalised lymphadenopathy is common worldwide. This small case series indicates that the Sri Lankan disease pattern of KD is almost similar to the already known pattern of disesase internationally. Awareness of its presence may help to make an early diagnosis of KD.

\section{References}

1. Kikuchi M. Lymphadenitis showing focal reticulum cell hyperplasia with nuclear debris and phagocytes. Acta Haematologica Japan 1972; 35: 379-80.

2. Fujimoto Y, Kozima Y, Yamaguchi K. Cervical subacute necrotizing lymphadenitis. A new clinicopathological entity. Naika 1972; 30: 920-7.

3. Sato Y, Kuno H, Oizumi K. Histiocytic necrotizing lymphadenitis (Kikuchi's disease) with aseptic meningitis. Journal of Neurological Sciences 1999; 163: 187-91.

4. Wano Y, Ebata K, Masaki Y, et al. Histiocytic necrotizing lymphadenitis (Kikuchi-Fujimoto's disease) accompanied by hemophagocytosis and salivary gland swelling in a patient with systemic lupus erythematosus. Rinsho Ketsueki 2000; 41: $54-60$.

5. Mahadeva U, Allport T, Bain B, Chan WK. Haemophagocytic syndrome and histiocytic necrotising lymphadenitis (Kikuch's disease). Journal of Clinical Pathology 2000; 53: 636-8.

6. Sharma OP. Unusual systemic disorders associated with interstitial lung disease. Current Opinion in Pulmonary Medicine 2001; 7: 291-4.

7. Yasukawa K, Matsumura T, Sato-Matsumura KC, et al. Kikuchi's disease and the skin: case report and review of the literature. British Journal of Dermatology 2001; 144: 885-9.

8. Vila LM, Mayor AM, Silvestrini IE. Therapeutic response and long term follow-up in a systemic lupus erythematosus patient presenting with Kikuchi's disease. Lupus 2001; 10: 126-8.

9. Yoshino T, Mannami T, Ichimura K, et al. Two cases of histiocytic necrotizing lymphadenitis (Kikuchi-Fujimoto's disease) following diffuse large B-cell lymphoma. Human Pathology 2000; 31: 1328-31.

10. Chan JK, Wong KC, Ng CS. A fatal case of multicentric Kikuchi's histiocytic necrotizing lymphadenitis. Cancer 1989; 63: 856-62.

11. Wong CY, Law GT, Shum TT, et al. Pulmonary haemorrhage in a patient with Kikuchi disease. Monaldi Archives for Chest Disease 2001; 56: 118-20.

12. Kuo TT. Kikuchi's disease (histiocytic necrotizing lymphadenitis). A clinicopathologic study of 79 cases with an analysis of histologicsubtypes, immunohistology, and DNA ploidy. American Journal of Surgical Pathology 1995; 19: 798-809.

13. ang YJ, Park KH, Seok HJ. Management of Kikuchi's disease using glucocorticoid. The Journal of Laryngology and Otology 2000; 114: 709-11.

14. Bosch X, Guilabert A, Miquel R, Campo E. Enigmatic KikuchiFujimoto disease: a comprehensive review. American Journal of Clinical Pathology 2004; 122: 141-52.

15. Katz RL. Cytologic diagnosis of leukemia and lymphoma. Values and limitations. Clinics in Laboratory Medicine 1991; 11: 469-99. 